\title{
ACUTE APPENDICITIS IN PREGNANCY From the Department of Obstetrics and Gynaecology The Middlesex Hospital
}

\author{
By A. L. T. Easton, M.B., B.Chir., F.R.C.S., M.R.C.O.G. \\ Late Senior Registrar
}

In 1892, Lawson Tait described a case in which four years previously he had successful diagnosed and removed the first acutely inflamed appendix (Shepherd, 1956). In the same year Wiggins reported a case of perforated appendix with a three-month foetus in utero in which he advised removal of the appendix, only to have his counsel rejected by the patient's relatives. She died of peritonitis and the pregnancy was found postmortem. Munde, in 1894 , appears to have reported the first successful American case to be treated by operation. Bahler (1908), and later Marbury (1953), both quote Hancock (1848) as having reported a case of perityphlitic abscess drained surgically in the puerperium, but it is doubtful from the history if this was in fact such a case. It seems more probable that he was dealing with a strangulated Richter's hernia.

The occurrence of five cases, in the past two years at the Middlesex Hospital, of this complication of pregnancy, has prompted a further study of the condition. A search through the records of the last I I years revealed only three others, making a total of eight cases in the period 19461956 inclusive. It is emphasised that only cases of acute appendicitis, confirmed by the operative findings and the histological report, have been included. One, case No. 7 , was treated conservatively whilst pregnant, but was subsequently found at laparotomy to have incontestable evidence of a recent attack of acute appendicitis. Six other patients, in which appendicectomy was performed for symptoms and signs suggesting appendicitis but where chronic disease or evidence of past inflammation only was found, have not been included.

These eight cases are related to a total number of deliveries in the same period of 8,608 patients, an incidence of one case in $\mathrm{I}, 078$ deliveries. However, as only two cases occurred among patients already booked for delivery at the Middlesex Hospital the true incidence is obviously much lower. Rosner, quoted by Bahler (1908), found 22 cases in 15,000 pregnancies, whereas Van Gordt also cited by Bahler, gave an incidence of three cases in 10,000 pregnancies. More recently Cosgrove (1937) counted 18 cases in 25,000 live births and Smith and Bartlett (1940), found 20 cases in 66,431 live births, an incidence of $I$ in $I, 389$ and $I$ in 3,322 respectively. Differing criteria as to the diagnosis accounts for much of this variation, and the present series more nearly approaches that of Cosgrove (1937). Others approaching the matter differently, have stated that from 1.9 per cent. to 2 per cent. of all women who have appendicitis are also pregnant (Baer, Reis and Arens, 1932, ando Johnson, 1944). The total number of appendicectomies performed at the Middlesex Hospital during the period under consideration on women between the ages of 16 to 45 years was $\mathrm{I}, 288$, of whom 14 were pregnant, and of whom only eight had acute appendicitis and were pregnant as well. This gives a figure of I.I per cent. which is not dissimilar to the aforementioned ones.

In the series under review three cases occurred in the last trimester, whilst of the remaining five, two occurred at 26 weeks maturity, and the rest (three cases), between 16 and 20 weeks maturity. The number is, however, small and therefore little can be inferred from these figures. Because of its rarity, few are likely to be seen even during the lifetime of a busy practising obstetrician.

\section{Case Histories}

Case No. 4: Mrs. S.G., aged 34 years; Gravida 2

L.M.P. October 5, I950. Admitted on June 7, 195I. During her pregnancy her blood pressure had tended to rise slightly. She was admitted at approximately 36 weeks maturity with a diagnosis of pre-eclamptic toxaemia. Blood pressure $190 /$ $120 \mathrm{~mm}$. Hg. No albuminuria but slight ankle oedma. On the following day she began to vomit. This continued into the second day, when she complained, in addition, of abdominal pain, which was worse on the right than on the left. 
On Examination. There was very marked tenderness on the right side of the uterus, and the loins were also tender. Her blood pressure was was $180 / 1$ ro mm. Hg. The foetal heart was heard. The vertex was presenting with the fundus at 36 weeks. That evening the temperature, which had been normal, rose to $99.6^{\circ} \mathrm{F}$., and the pulse to 132 beats per minute. The blood pressure was now $140 / 90 \mathrm{~mm}$. Hg. A diagnosis of concealed accidental haemorrhage was made, and it was decided to treat her by caesarean section.

Operation. The abdomen was opened through a mid-line sub-umbilical incision, when pus was found on opening the peritoneum. The uterus was quite normal. A second incision, a McBurney was made, and a gangrenous perforated appendix was found lying retro-caecally and removed. Both incisions were closed with drainage to the wounds only. She was given a blood transfusion and was treated post-operatively by gastric suction and intravenous electrolytes together with systemic penicillin and streptomycin. Her recovery was steady, and three weeks later, was delivered of a live child.

Case No. 5 : Mrs. P.H., aged 22 years; Primigravida

Her expected date of delivery was January 25, 1957. She was admitted to Hospital when 26 weeks pregnant on October 19, with a history of upper abdominal pain followed by vomiting for three days. The pain was referred to the back as well, and occurred in spasms. On the second day of her illness, she complained of diarrhoea which was soon followed by constipation. Foetal movements were felt.

On Examination. She looked ill. Her temperature was $99.6^{\circ} \mathrm{F}$., pulse roo. The tongue was moist and slightly coated and there was some foetor. Per abdomen the uterus was consistent with a pregnancy of 26 weeks. The epigastrium was somewhat distended and there was marked tenderness and rebound tenderness in the right iliac fossa. The foetal heart was heard and the foetal movements felt.

Investigations. C.S.U. No pus cells or organisms. Blood count: W.B.C., I 7,000 per c.mm.; polymorphs, 92 per cent.; lymphocytes, 5 per cent; and monocytes, 3 per cent. X-ray of abdomen: no fluid levels seen.

Operation. A right paramedian incision. A gangrenous retro-caecal appendix containing a faecolith was found and removed. The abdomen was closed without drainage. Post-operatively she was given pethidine $100 \mathrm{mg}$. four-hourly, streptomycin $\frac{1}{2}$ g. b.d. A Ryles tube was passed and an intravenous drip set up. She made a steady recovery but on the third day after operation she aborted. The foetus weighed $2 \mathrm{lb} .6 \mathrm{oz}$. and died five hours later. Culture of peritoneal swab showed a moderate growth of coliforms insensitive to penicillin, erythromycin and sulphanilamide.

Case No. 6: Mrs. M.L., aged 26 years; Gravida 3 L.M.P. June 20, 1956. Maturity 16 weeks. Admitted October 21, 1956, complaining of anorexia, nausea and vomiting for some days. At first she considered her symptoms no worse than she had experienced in her previous pregnancies. For two days she had lower abdominal pain which became referred to the right flank on the day before admittance, and more recently was felt in the shoulder. She further stated that this was aggravated by deep breathing and was associated with a rigor.

On Examination. She looked ill and was in pain. The respirations were shallow and rapid. Temperature IOI $^{\circ} \mathrm{F}$., pulse I $^{\circ}$. There was no cyanosis and the alae nasae were working. The chest was normal. Blood pressure $130 / 80 \mathrm{~mm}$. Hg. Per abdomen the uterus was consistent with her dates. There was marked tenderness and guarding in the right loin, and the right iliac fossa and lower abdomen. Rectal examination showed a very tender pouch of Douglas.

Investigations. Chest X-ray normal. C.S.U. No pus cells or organisms. Diagnosis of general peritonitis resulting from acute appendicitis was made.

Operation. The abdomen was opened through a McBurney's incision without delay. Free pus appeared on opening the peritoneum. A gangrenous perforated retro-caecal appendix was removed and the abdomen closed with drainage to the wound. The post-operative treatment consisted of gastric suction, an intravenous drip and parenteral penicillin and streptomycin. Culture of peritoneal swab grew profuse B. Coli sensitive to chloromycetin. A coliform wound infection which developed on the Ioth day, causing a temperature of $100^{\circ} \mathrm{F}$. was insensitive to chloromycetin.

She was discharged three weeks after operation, but aborted I I days later a macerated foetus. On this occasion she had a rigor and a temperature of $102^{\circ} \mathrm{F}$, , but culture of a vaginal swab showed no pathogenic organism.

Case No. 7: Mrs. F.P., aged 28 years; Primigravida

Admitted in 1946 . Maturity 36 weeks. She gave a history of vomiting followed by lower abdominal pain which localized to the right iliac fossa on the day after its onset. Total duration of symptoms before admission: 72 hours. The symptoms, however, had been preceded by anorexia and diarrhoea for some days.

On Examination. Temperature 100.4 ${ }^{\circ} \mathrm{F}$., pulse 
TAQLE I

ACUTE APPENOICITIS IN PREGNANCY

PHYSICAL SIGNS

\begin{tabular}{|c|c|c|c|c|c|c|c|c|c|c|c|c|c|c|c|c|}
\hline & \multirow[b]{2}{*}{ Age } & \multirow[b]{2}{*}{$\left|\begin{array}{l}\text { Mor- } \\
\text { urity }\end{array}\right|$} & \multirow[b]{2}{*}{ Temp. } & \multirow[b]{2}{*}{ Pulse } & \multirow[b]{2}{*}{ Vomit } & \multirow[b]{2}{*}{ Foperor } & \multirow[b]{2}{*}{ Tongue } & \multirow[b]{2}{*}{ Guord. } & \multirow[b]{2}{*}{$\begin{array}{l}\text { Rov- } \\
\text { sing }\end{array}$} & \multirow[b]{2}{*}{$\begin{array}{l}\text { Re- } \\
\text { bound }\end{array}$} & \multirow{2}{*}{$\begin{array}{l}\text { Dur- } \\
\text { orion. } \\
\text { (hrs) }\end{array}$} & \multirow[b]{2}{*}{$\begin{array}{c}\text { Tenoter- } \\
\text { ness. }\end{array}$} & \multirow[b]{2}{*}{ c.S.U. } & \multirow[b]{2}{*}{ Pothology } & \multicolumn{2}{|c|}{ Aesure } \\
\hline & & & & & & & & & & & & & & & Mother & Child \\
\hline 1 & 21 & 20 & 98 & 94 & + & none & nurred & - & + & + & 36 & R.I.F & $\begin{array}{c}\text { nor } \\
\text { stored }\end{array}$ & Gongrenous & $A$ & ND. \\
\hline 2 & 30 & 26 & 1004 & 120 & $t$ & none & cleon & - & - & + & 72 & RI.F. & E.C. & Gongrenous & $A$ & $C S$ \\
\hline 3 & 36 & 16 & 101 & 130 & + & mild & hurred & - & - & - & 48 & B.I.F & E.C. & Perforoted & $A$ & $A B$ \\
\hline 4 & 34 & 36 & 99 & 130 & + & $\begin{array}{c}\text { not } \\
\text { stoted }\end{array}$ & $\begin{array}{c}\text { nor } \\
\text { stored }\end{array}$ & - & - & - & 48 & RIF & E.C. & $\begin{array}{l}\text { Perforofed } \\
\text { Perocoecal }\end{array}$ & $A$ & ND. \\
\hline 5 & 22 & 26 & 99.6 & 100 & + & morked & furred & - & - & - & 72 & RUF & E.C. & Gongrenous & $A$ & $A B$ \\
\hline 6 & 26 & 16 & $101 \cdot 4$ & 140 & + & none & ckeon & - & - & + & 48 & $\begin{array}{l}\text { R.Loin } \\
\text { Shoulder }\end{array}$ & E.C. & $\begin{array}{l}\text { Pertoroted } \\
\text { Aetrocoecol }\end{array}$ & $A$ & $A B$ \\
\hline 7 & 28 & 36 & 1004 & 146 & + & $\begin{array}{l}\text { not } \\
\text { stored }\end{array}$ & $\begin{array}{c}\text { nol } \\
\text { stored }\end{array}$ & - & - & - & 72 & RIF. & $\begin{array}{r}E C . C \\
R B . C . \\
W B . C .\end{array}$ & $\begin{array}{l}\text { Subsequent } \\
\text { Appendicectiony } \\
\text { Obliterotive }\end{array}$ & $A$ & $S B$. \\
\hline 8 & 21 & 32 & 90.4 & 124 & + & shight & cheon & + & + & + & 24 & RIF & E.C. & $\begin{array}{l}\text { Eorly ocute } \\
\text { Pecurrent }\end{array}$ & $A$ & $N$ \\
\hline
\end{tabular}

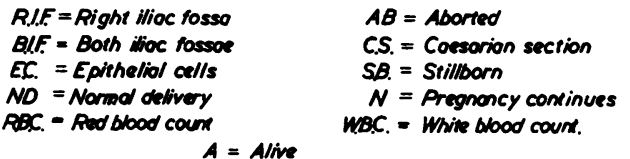

i3o. The uterus was enlarged to 36 weeks. There was tenderness on the right side of the abdomen. C.S.U. showed R.B.C. and W.B.C., but no organisms. A diagnosis of acute appendicitis was made, and it appears from the notes that it was decided to treat her conservatively. She was given penicillin 50,000 units and sulphathiazole I g. four-hourly. The temperature ranged between 99 and $100.6^{\circ} \mathrm{F}$.

Four days after admission she went into premature labour and was delivered with forceps of a stillborn macerated infant. It appears that the foetal heart was not heard for some time before delivery, but the precise moment is not known. A fortnight after admission her temperature again rose to $101.4^{\circ} \mathrm{F}$. and the notes state that a tender mass became palpable below the right costal margin. This subsided without treatment and, before her discharge from Hospital, an X-ray Barium enema showed no filling of the appendix. Four months later she was readmitted for an interval appendicectomy. This was done through a grid-iron incision, when a completely fibrotic appendix, whose tip had vanished, was removed. There were few adhesions.

\section{Diagnosis}

Acute appendicitis in pregnancy differs little in history and physical signs from the non-pregnant save in one or two of the abdominal findings. Table I shows the relevant details of each case, and from it one can see that guarding is absent in all cases except one. Rebound tenderness, a sign of parietal peritoneal irritation, was noted in hat $c$ the cases only. Nausea and vomiting always occur. and the cases presented show no exception to thi rule.

However, it should be remembered that such $\bar{\partial}$ symptoms are not infrequently associated with normal pregnancy and this may lead the unwary $\stackrel{\mathbb{Q}}{\mathscr{2}}$ into errors in diagnosis.

The absence of guarding over the right iliac fossa due to the presence of an enlarged uterus has been noted by some, but others speak of rigidity being present (Browne, I95I). It must be remembered that the abdominal wall relaxes considerably to accommodate the increase in its contents during pregnancy without rise in tension, and possibly an alteration in muscle tone or function may be added to the anatomical change. This is, of course, purely speculative but may account for the lack of guarding. One fact is certain, and that is that tenderness, often acute, is present on the right side of the abdomen in every case.

There is another factor that will alter the picture. With advancing pregnancy there goes an alteration in the position of the caecum and appendix. An upward displacement of the viscera has been ably demonstrated radiologically by Baer and his associates (1932). They have shown that a ? progressive upward movement of the caecum $T$ occurs and that the appendix, in addition, is rotated in a counter-clockwise direction. This 
results in the appendix becoming an upper abdominal organ and leads to confusing physical signs when it is inflamed. Its distinction from cholecystitis then becomes a matter for some circumspection, particularly when, as occurred in case No. 6, perforation had occurred and shoulder tip pain was present on the right side.

The presence of a coated tongue and oral foetor, so often relied on, can be seen to have been an inconstant finding, though in two instances no mention of this is made in the records. The pulse-rate proved to be a more reliable guide than the temperature, though it should be emphasised that with fluctuations in the latter, a normal reading should be repeated after an interval before being accepted as such.

Vaginal and rectal examinations are seldom helpful, the less so as the pregnancy matures, though where generalized peritonitis has occurred the pouch of Douglas will be felt to be tender. This was found in case No. 6. With advancing pregnancy the recto-uterine pouch becomes reduced and its contents become displaced by the foetal head.

An analysis of 16 incorrectly diagnosed cases has shown that pyelitis, torsion of the pedicle of an ovarian cyst, and acute gastroenteritis were among the commonest errors, whilst salpingitis or ruptured pyosalpinx are also reported (Child and Douglas, 1944; Evans, 1955). Again, right basal pneumonia, cholecystitis and intestinal obstruction have been mistaken in the past for appendicitis (Browne, r95I).

More commonly, the diagnosis must be made from ruptured tubal pregnancy, in the early months, torsion of a pedunculated fibroid or degeneration in an intramural or pedunculated myoma. In ectopic gestation the pain of tubal colic, together with signs of peritoneal irritation from the leakage of blood through the abdominal ostium, may closely simulate acute appendicitis. Such pain, however, is more paroxysmal in nature and the temperature, if raised, is only very slightly so.

In late pregnancy the possibility of the case being one of concealed accidental ante-partum haemorrhage must be borne in mind while at all times pyelitis should be excluded. In the latter, the pain tends more to the loin, there is frequency of micturition and rigors are seldom absent. A catheter specimen of urine should in all cases be examined for pus cells and organisms. Nevertheless, a gangrenous perforated retro-caecal appendix may closely simulate pyelitis, as in case No. 6. Red blood cells may also appear in the urine, as in case No. 7, which is attributed to proximity of an inflamed appendix to the ureter causing ureteritis (Bahler, 1908), whilst the urine of normal pregnant women is said to grow Bacillus Coli in I I per cent. of cases (Dodds, I93I).

The passage of a ureteric calculus may also mimic the disease, particularly as there will be frequent vomiting. I have seen such a case elsewhere when this proved to be so.

\section{Other Investigations}

The leucocyte count would seem to be of even less value than in the uncomplicated case because of the physiological leucocytosis of pregnancy. A high total count, over 14,000 , with a dominance of young polymorphonuclear leucocytes, will be significant, but a negative finding does not exclude appendicitis. Radiological examination of the abdomen is seldom of value and is probably contraindicated on the grounds of unnecessary delay and disturbance to the patient.

\section{Discussion}

A maternal mortality of 0.71 per cent. when the disease is confined to the appendix, 30 per cent. when there is peritonitis, and 50 per cent. when the appendix is perforated is to be found (Meiling, 1947). These figures are largely based on pre-war cases and are alarming. But the recently collected results of nine authors show a maternal death rate of 5.8 per cent. in all of 206 cases. Of even greater significance is the fact that cases occurring in the last three months of pregnancy show a mortality of 20.7 per cent. (Parker, 1954). Clearly patients with this disease are worse off than if they had not been pregnant.

What are the results as far as the pregnancy is concerned ? All are agreed that the patient with a perforated appendix stands something in the region of a 50 to 80 per cent. chance of abortion or premature labour, while the acute non-perforated case may show a 30 per cent. chance of abortion. Lower estimates occur in the first trimester and include many normal and chronic appendicitis cases. These show little variation from the expected incidence of abortion in uncomplicated pregnancy. Most workers can point to a marked increase in abortion rate in the perforated as distinct from the non-perforated case (Bahler, I908; Child and Douglas, I944; Hoffman and Suzuki, 1949). In the series under review, 50 per cent of the foeti were lost and in six cases the appendix was known to be gangrenous or perforated. In one instance, case No. 7, a stillborn infant was delivered after being allowed to remain several days in the presence of an acute attack that probably did not result in perforation. Of the three patients who perforated their appendix, cases 3,4 and 6, two aborted and one was delivered of a live child at term. Of the four other cases of non-perforated appendicitis, subjected to im- 
mediate operation, cases $1,2,5$ and 8 , only one aborted. Case No. 8 was operated on after minimal delay from the onset of symptoms, and had not progressed beyond the stage of acute catarrhal inflammation; the pregnancy continues normally.

In the eight cases presented no mother died, four infants were lost, three were delivered of live children, one by caesarean section for foetal distress at term I4 weeks later. The most recent patient, case No. 8 , at the time of writing is still pregnant and expects to be confined after March I, 1957. These show an overall foetal loss of 50 per cent.

That the patient who was treated conservatively at 36 weeks maturity survived to have an interval appendicectomy, is a tribute to the effectiveness of chemotherapy. She was delivered, four days after admission, of a stillborn macerated child and subsequently ran a pyrexial course developing a mass on the right side of the abdomen. Later an obliterated appendix with evidence of past inflammation was removed. The remaining seven cases were treated by immediate appendicectomy.

Attention has been drawn to the increase in mortality in the later months of pregnancy, and this is attributed in part to delay in treatment due essentially to difficulty in diagnosis. Three factors conspire to bedevil the picture and, by the subsequent delay, place the patient in special hazard. Mention has already been made of the displacement of the appendix upward into the abdomen. This alters the position of the signs and varies the symptoms and thus confuses the picture. Next, the appendix, now an upper abdominal organ, lies in contact with coils of upper intestine and alongside a large globe-shaped contractile organ, the uterus. Should perforation occur, localization of an abscess is made difficult or impossible for the following reason. Whereas, in the presence of peritonitis the alimentary viscera cease movement, the uterus does the reverse. All attempts at adhesion formation to localize the infection will be nullified by such movement. Labour and delivery, because of the associated rapid diminution in the uterine volume, will further aggravate the condition as the inner wall of the abscess cavity will be torn away and all adhesions broken.

When localization has occurred, removal of the appendix, the centre of the infection, is done at the price of breaking down many adhesions. If an expectant policy is advocated, it should be done in the full knowledge that the patient will almost certainly abort and reproduce the operative interference without the benefit of having the appendix removed first.

Lastly, another factor which may contribute to the delay is the clinician's disinclination to perform laparotomy at, or near, term in the presence of an otherwise normal pregnancy. The penalties of a missed appendicitis justify the occasional unnecessary laparotomy. Most authors agree that pregnant women tolerate even major surgical procedures quite as well as the nonpregnant, though under ordinary circumstances, operation at the r2th week is best avoided for fear of precipitating miscarriage.

Any disagreement with the view that immediate appendicectomy should be done dates largely from the time when the controversy centred round the treatment of acute appendicitis in general. Since this issue is now settled, there seems little point in differentiating the pregnant from the nonpregnant.

The earliest observations on the high mortality of the disease attributed this entirely to the high position of the appendix and consequent poor powers of localization. This prompted a move towards immediate evacuation of the uterus irrespective of the maturity. Instead of treating the disease on its merits and allowing the pregnancy to remain undisturbed, a spate of caesarean sections, caesarean hysterectomies, and surgical inductions were done with disastrous results (Cosgrove, 1937; Priddle and Heseltine, 1951).

Despite this, the perforated appendix in the last month of pregnancy where a viable child with a reasonable chance of extra-uterine survival exists, merits special consideration. Quite apart from the likelihood of premature labour, there exists a special risk of intra-uterine foetal death if the infant is allowed to remain in utero in the presence of peritonitis. It is recognized that this may occur in any severe constitutional disease, and is probably due to the continuation of high pyrexia together with bacterial toxaemia. It is not quite clear why this should occur, but perhaps it would not be out of place to indulge in a little speculation. The prolonged rise in temperature must increase the metabolic rate and therefore the oxygen requirements of the fast developing tissues. It is possible that a point is reached when the demand outstrips the supply, and this at a time when the placental efficiency is diminishing. In addition, it is recognized that fast growing tissues are especially susceptible to noxious stimuli. One author suggests that acidosis occurring in a case of perforated appendicitis post-operatively was responsible for an intra-uterine death and recommends early infusion with 5 per cent. sodium bicarbonate (De Voe, 1947).

How then can the infant be spared this risk of intra-uterine death, whatever its cause? In general operative manoeuvres to terminate the pregnancy are contra-indicated, save where forceps delivery can the more rapidly complete the second 
stage of a spontaneous labour, and where lower segment caesarean section is done for an overiding obstetrical reason.

The view that, where peritonitis is present, caesearean section should be performed, is roundly condemned by several authors (Bahler, 1908; Hoffman and Suzuki, 1949; Cosgrove, I937; . De Voe et al., I947) though caesarean hysterectomy in the more severe cases of abscess formation may prove life saving.

There seems little doubt that the best way to save the child is to remove the appendix before perforation and peritonitis occur. Furthermore, it is doubtful if, even with modern powerful antibiotics, it is ever justifiable to incise the uterus in the presence of such peritonitis, though there is room for legitimate differences of opinion here, especially at term.

Where abscess formation has already occurred, a special case for early drainage exists, since the patient here is in very grave danger. The abscess, as has been pointed out, will surely rupture when abortion or premature labour occurs.

In general, removal of the appendix should be supplemented by anti-biotic treatment with careful regulation of fluid and electrolyte balance, if the foetal as well as maternal death rates are to be further reduced. A significant improvement in the mortality from perforated appendicitis may, in part, be due to the use of antibiotics. While this may be true, the improvement must also be due to increase in awareness of the condition by the practitioner and improvement in therapeutic standards and efficiency in general. A greater willingness on the part of the patients to seek early treatment, improved nutrition and living standards, all play their part.

Where there is severe respiratory embarrassment, as occasionally occurs, induction of labour by surgical rupture of membranes after appendicectomy provides the quickest relief (Parker, 1954).

\section{Incision}

Opinion is divided, but both from experience of these recent cases and from general considerations it is obvious that, provided no attempt at caesarean section is to be made, a high McBurney incision provides the best access to the appendix. Its level is dictated by the maturity of the pregnancy and its use results in minimal disturbance to the uterus itself. Its only drawback would seem to be when the diagnosis is in error. However, it is to be hoped that this will seldom prove to be the case. Midline and paramedian incisions result in difficulty of access and much pressure and handling of the uterus in order to reach the appendix.
Drainage of the peritoneum is, on the whole, less important than drainage of the wound itself.

The post-operative treatment includes intravenous drip and gastric suction when ileus occurs. Appropriate antibiotics should be used and of even greater importance is prolonged and adequate sedation to minimise the chance of abortion or premature 'labour. Morphine,' or allied drugs, given 4 to 6 hourly for up to three days, is desirable. It is probable that insufficient attention has been paid to this aspect in the cases presented and this may in part have contributed to the high abortion rate.

\section{Conclusion}

It seems that Bahler's precept of 1908 , concerning the dangers of delay has not; in the light of recent advances in technique, knowledge and therapy, been in any way modified. The early removal of the appendix provides the best chance both to mother and infant of survival. A disease which carries with it a maternal mortality of over 20 per cent. in the last trimester of pregnancy, and an overall foetal loss of 50 per cent. deserves the most strenuous efforts at improvement.

\section{Summary}

I. Eight cases of acute appendicitis complicating pregnancy are reviewed.

2. No mother died and four infants were lost:

3. A higher foetal loss occurred in those cases of perforated appendix than in the non-perforated.

4. Attention is drawn to the dangers both to mother and infant of peritonitis resulting from poor localization of the infection.

5. Appendicectomy in pregnancy, even when the diagnosis is in doubt, will help to avoid the lethal combination in the last trimester.

6. There is no place for the conservative treatment of acute appendicitis in pregnancy.

\section{Acknowledgments}

I wish to thank Mr. R. V. Hudson, Mr. W. R. Winterton, Mr. Ian Jackson and Mr. R. S. Handley for permission to publish these cases. Also I would like to thank Mr. F. W. Roques, Mr. W. R. Winterton and Mr. L. P. Le Quesne for their kind help and guidance in preparing this article. Also Miss Fisher, of the Records Department, The Middlesex Hospital, who prepared the table.

\section{BIBLIOGRAPHY}

BAER, J. L., REIS, R. A., and ARENS, R. A. (1932), F. Amer. med. Ass., 98, 1359 .

BAHLER, E, A. (I908), Ibid., 51, I310. MaCLEOD, D. (1938), BERKELEY, C., BONNEY, V., and MacLEOD, D.

BROWNE, F. J. (195I), 'Ante-natal and Post-natal care,' Churchill, London, p. 435.

Bibliography continued on page 286 
present in 87 per cent. at the knees and in 56 per cent. at the ankle in the age-group 60-75 years. The neurological findings in our patients over 6o years were specially scrutinized, and where possible those considered to be due to senility were excluded.

TABLE I

\begin{tabular}{|c|c|c|c|c|}
\hline $\begin{array}{c}\text { Type of Neurological } \\
\text { Disorders }\end{array}$ & Males & Females & Total & $\begin{array}{l}\text { Per } \\
\text { cent. }\end{array}$ \\
\hline S.C.D. $\left\{\begin{array}{l}\text { Myelopathy } \\
\text { Myelopathy } \\
\text { and Neuro- } \\
\text { pathy }\end{array}\right.$ & 7 & 24 & $3 \mathrm{I}$ & 28 \\
\hline $\begin{array}{l}\text { Neuropathy } . \\
\text { Pernicious anaemia }\end{array}$ & 3 & ro & I3 & 12 \\
\hline $\begin{array}{lll}\text { alone } & \ldots & \ldots\end{array}$ & 20 & 33 & 53 & 48 \\
\hline Totals & 30 & 80 & 110 & 100 \\
\hline
\end{tabular}

I 10 cases of pernicious anaemia:

With neurological signs $\quad \ldots \quad$. $\quad 5 \quad 57$

Without neurological signs .. $\quad \ldots \quad 53$

As will be seen from Table $\mathrm{I}$ neurological signs were present in 57 of our I IO cases. In 13 (12 per cent.) the picture was one of uncomplicated neuropathy, whilst in the remaining 44 there was unmistakable evidence of cord damage of postero-lateral column type, either pure (3I cases ( 28 per cent.)), or mixed with peripheral nerve lesions ( 13 cases ( 12 per cent.)). Thus 40 per cent. of our series of 1 Io cases of pernicious anaemia had definite evidence of subacute combined degeneration of the cord. No correlation was apparent between the severity of the anaemia and the presence of neurological signs of any sort. In fact six patients with S.C.D. had red blood cell counts of 4.5 million or over.

Examination of the age of onset of symptoms showed that the majority ( 36 of a total of 53$)$ with pernicious anaemia alone were over 55 , and that those with neurological signs were again more numerous over this age ( 37 of a total of 57 ). These figures suggest that the incidence of neurological complications is no higher in the young than in the old. Lastly, an attempt was made to correlate the length of history of illness with the appearance of neuropathy or myelopathy. Statistical analysis showed no significant difference between the group with pernicious anaemia and those with nervous semeiology.

The efficacy of therapy in those with neurological signs could not be assessed, for during the period under study there was a great influx of new liver preparations, and vitamin $B_{12}$ became available during the latter years. However, only one case of S.C.D. relapsed after reaching maximal improvement. This patient had stopped liver therapy for six months and at the end of this period both the anaemia and the S.C.D. had progressed markedly.

This series shows a preponderance of female (80) over male $(30)$ cases. No satisfactory explanation could be found for this bias of case selection, but it is of interest that this trend is a constant feature of the analysis of all case-records of the United Birmingham Hospitals, 1950-55 (Waterhouse personal communication).

\section{Summary}

A survey of I Io cases of pernicious anaemia is presented. Subacute combined degeneration of the cord was present in 40 per cent. All cases of senile neurological degeneration were excluded. The signs of S.C.D. were not related to length of symptoms of $\mathrm{B}_{12}$ deficiency, the age of the patient or the degree of anaemia. This high figure stresses the need for careful neurological examination in the diagnosis and follow-up of pernicious anaemia.

\section{Acknowledgments}

We wish to thank Dr. Michael Jefferson and Dr. J. Waterhouse for their advice and criticism, and Miss Ellis for her secretarial assistance.

\section{REFERENCES}

1. YOUNG, R. H. (1932), F. Amer. med. Ass., 99, 612.

2. WOLTMANN, H. W. (1919), Amer. F. med. Sci., 157, 400.

3. HOWELL, T. (1949), Lancet, i, 56.

Bibliography continued from page 277-A. L. T. Easton, M.B., B.Chir., F.R.C.S., M.R.C.O.G.

CHILD, C. G., and DOUGLAS, R. G. (1944), Amer. F. Obstet. Gynec., 47, 213.

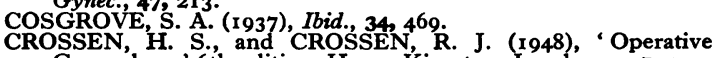
Gynecology,' 6th edition, Henry Kimpton, London, p. 721. DE VOE, R. W., DAY, L. A., FERRIS, D. O. (1947), Proc. Mayo Clin., 22, 135.

DODDS, G. H. (193 I), ₹. Obstet. Gynaec. Brit. Emp., 38, 773.

DONALD, I. (x955), 'Practical Obstetric Problems,' Lloyd Luke, London, p. 100 .

EVANS, L. A. (1955), Proc. roy. Soc. Med., 48, 1090.

HANCOCK, $\mathbf{H}$. (1848), Lancet, ii, $38 \mathrm{r}$.

HEATON, G. (1905), Brit. med. $\mathcal{F}$., i, 463.

HOFFMAN, E. S., and SUZUKI, M. (1949), West F. Surg., 57,150 .

JOHNSON, B. (1944), Med. F. Aust., ii, 379.

KRIEG, E. G. M. (1949), Amer. F. Obstet. Gynec., 57, 736.
KERR, J. M. M., and MOIR, J. C. (1956), 'Operative Obstetrics,' 6th edition, London, p. 437.

MARBURY, W. B. (1933), Amer. F. Surg., 19, 437.

MCDONALD, A. L. (1929), Amer. F. Obstet., 18, 1 io.

MEILING, R. L. (1947), Surg. Gynec. Obstet., 85, 512.

MEYER, R. A., REQUARTH, W. H., and KOZOLL, D. D (1946), Amer. F. Surg., 72, 830.

MUNDE, P. F. (1894), Med. Rec., xlvi, 678.

MUNDE, P. F. (1895), Mbid., xlvii, 28 and 379.

PARKER, R. B. (1954), Lancet, i, 1252 .

PRIDDLE, H. D., and HESELTINE, H. C. (1951), Amer. $\mathcal{f}$ Obstet. Gynec., 62 , 150 .

SHEPHERD, J. A. (I956), Lancet, ii, I 301 .

SMITH, J. A., and BARTLETT, M. K. (I940), Nero Engl. F. Med. WAƯG, 529.

Surg. Clin. N. Amer, 23, I 144

WIGGINS, F. H. (1892), Med. Rec. xli, 109. 